\title{
Vitamin D deficiency causes insulin resistance by provoking oxidative stress in hepatocytes
}

\author{
Sha Tao ${ }^{1, *}$, Qi Yuan ${ }^{1, *}$, Li Mao ${ }^{1}$, Feng-Li Chen ${ }^{2}$, Feng $\mathrm{Ji}^{3}$ and Zhao-Hui Cui ${ }^{1}$ \\ ${ }^{1}$ Department of Endocrinology, Huai'an First People's Hospital, Nanjing Medical University, Huai'an, China \\ ${ }^{2}$ Clinical Laboratory, Huai'an First People's Hospital, Nanjing Medical University, Huai'an, China \\ ${ }^{3}$ Department of Orthopedics, Huai'an First People's Hospital, Nanjing Medical University, Huai'an, China \\ *These authors are considered as co-first authors \\ Correspondence to: Li Mao, email: hamaoliys@163.com \\ Feng Ji, email: huaiaifengjidr@163.com \\ Keywords: vitamin D, insulin resistance, oxidative stress, hepatocytes, N-acetylcysteine (NAC) \\ Received: April 21,2017 Accepted: May 23, $2017 \quad$ Published: June 28, 2017 \\ Copyright: Tao et al. This is an open-access article distributed under the terms of the Creative Commons Attribution License 3.0 \\ (CC BY 3.0), which permits unrestricted use, distribution, and reproduction in any medium, provided the original author and source \\ are credited.
}

\section{ABSTRACT}

Vitamin D deficiency could cause insulin resistance. However, the underlying mechanisms are unclear. The $1 \alpha-H y d r o x y l a s e ~[" 1 \alpha(\mathrm{OH})$ ase"] is a key enzyme for activate vitamin D3 synthesis. Here, we show that $1 \alpha(\mathrm{OH})$ ase stable knockdown by targeted shRNA led to vitamin D3 depletion in L02 hepatocytes. $1 \alpha(\mathrm{OH})$ ase silence also inhibited insulin-induced downstream signaling (IRS-1, ERK and AKT) transduction and glucose transporter 4 expression. Further, $1 \alpha(\mathrm{OH})$ ase shRNA in L02 hepatocytes led to significant reactive oxygen species production, p53-p21 activation and DNA damages. Such effects were almost completely reversed with co-treatment of n-acetylcysteine, which is an established anti-oxidant. Remarkably, insulin-induced downstream signaling transduction and glucose transporter 4 expression were recovered with $n$-acetylcysteine co-treatment in $1 \alpha(\mathrm{OH})$ ase-silenced $\mathrm{LO2}$ hepatocytes. Together, our results suggest that vitamin D deficiency-induced insulin resistance is possibly caused by oxidative stress in hepatocytes.

\section{INTRODUCTION}

Insulin resistance is a major reason of type-II diabetes $[1,2]$. It is also a characteristic manifestation of a wide range of other clinical diseases [3-5]. A number of genetic and/or environmental factors could cause insulin resistance [3-5]. Epidemic studies have suggested that that vitamin $\mathrm{D}$ deficiency is also associated with insulin resistance [6]. The supplementation of active vitamin D3 may help to improve the insulin resistance [6]. However, the underlying mechanism is largely unknown [6].

The function of reactive oxygen species (ROS) in insulin resistance has been well established [7-9]. Studies have demonstrated that ROS level is significantly increased in both clinical samples and experimental settings of insulin resistance [10-12]. Meanwhile, exogenous oxidative stress would lead to insulin resistance. These results suggest that oxidative stress might play a key function in insulin resistance $[7,9]$. Inhibition of ROS, on the other hand, could improve insulin sensitivity and glucose homeostasis in insulinresistant mice [10-12]. Clinical studies have also shown that supplement with anti-oxidant may improve insulin sensitivity [10-12].

25 -Hydroxyvitamin D3 $1 \alpha$-Hydroxylase ["1 $\alpha(\mathrm{OH})$ ase"] is a key enzyme for activate vitamin D3 synthesis $[13,14]$. In the current study, $1 \alpha(\mathrm{OH})$ ase was silenced in human L02 hepatocytes to mimic vitamin D deficiency. Our results suggest that vitamin D deficiency induces insulin resistance probably by provoking oxidative stress. 


\section{RESULTS}

\section{Knockdown of $1 \alpha(\mathrm{OH})$ ase leads to vitamin D3 depletion in L02 hepatocytes}

In order to mimic vitamin $\mathrm{D}$ deficiency in vitro, shRNA strategy was applied to knockdown vitamin D3 $1 \alpha$-Hydroxylase [" $1 \alpha(\mathrm{OH})$ ase"] in human $\mathrm{L} 02$ hepatocytes. $1 \alpha(\mathrm{OH})$ ase is required for vitamin D3 synthesis [13]. As described, two distinct lentiviral shRNAs ("-1/-2"), targeting non-overlapping sequences of human $1 \alpha(\mathrm{OH})$ ase, were applied. Western blotting assay results showed that stable introduction (via lentiviral infection) of either shRNA led to dramatic downregulation of $1 \alpha(\mathrm{OH})$ ase protein in L02 hepatocytes (Figure 1A). Meanwhile, $1 \alpha(\mathrm{OH})$ ase $m R N A$ was almost completely depleted by the targeted shRNA (Figure 1B). Consequently, the cellular content of vitamin D3 was dramatically reduced in $1 \alpha(\mathrm{OH})$ ase-silenced L02 hepatocytes (Figure 1C). Notably, the scramble control shRNA ("sh-SCR") had no significant effect on $1 \alpha(\mathrm{OH})$ ase expression nor vitamin $\mathrm{D} 3$ content. Together, these results demonstrate that $1 \alpha(\mathrm{OH})$ ase knockdown by targeted shRNAs leads to vitamin D3 depletion in human L02 hepatocytes.

\section{Knockdown of $1 \alpha(\mathrm{OH})$ ase leads to insulin resistance in $\mathrm{LO2}$ hepatocytes}

The aim of this study is to test the potential effect of vitamin $\mathrm{D}$ deficiency on insulin resistance. The $1 \alpha(\mathrm{OH})$ ase-silenced L02 hepatocytes (See Figure 1) were thereby treated with insulin. Western blotting assay was performed to test insulin signalings $[15,16]$. Results in Figure $2 \mathrm{~A}$ demonstrated that insulin $(1 \mu \mathrm{g} / \mathrm{mL}, 10 \mathrm{~min})$ induced activation of downstream signalings, including IRS-1 (insulin receptor substrate-1), ERK1/2 and AKT, was largely inhibited with $1 \alpha(\mathrm{OH})$ ase knockdown. Phosphorylated ("p-") IRS-1, p-AKT and p-ERK1/2 by insulin were all dramatically reduced in $1 \alpha(\mathrm{OH})$ ase-depleted L02 hepatocytes (Figure 2A). Expression of above total kinases was yet unchanged (Figure 2A). Quantified results summarizing three sets of repeated blot data further confirmed inhibition of insulin-induced IRS1, ERK $1 / 2$ and AKT activations with $1 \alpha(\mathrm{OH})$ ase silence in L02 hepatocytes (Figure 2B). Meanwhile, as shown in Figure 2C, expression of glucose transporter 4 (GLUT4), a key glucose transporter protein, was also downregulated in $1 \alpha(\mathrm{OH})$ ase-silenced L02 hepatocytes (Figure 2C). Together, these results imply that knockdown of $1 \alpha(\mathrm{OH})$ ase might lead to insulin resistance in L02 hepatocytes.

\section{Knockdown of $1 \alpha(\mathrm{OH})$ ase leads to ROS production, p53-p21 activation and DNA damage in L02 hepatocytes}

It has been previously shown that vitamin $\mathrm{D}$ and $1 \alpha(\mathrm{OH})$ ase are both involved in prevention of oxidative stress [17-19]. Vitamin D activates vitamin D receptor (VDR) to increase activity of superoxide dismutase (SOD), phospholipid hydroperoxide glutathione peroxidase (GSH-Px) and other anti-oxidant enzymes [19], thereby suppressing oxidative stresses [19]. Further, ROS production could be an important contributor of insulin resistance $[8,9]$. Here, we found that SOD activity
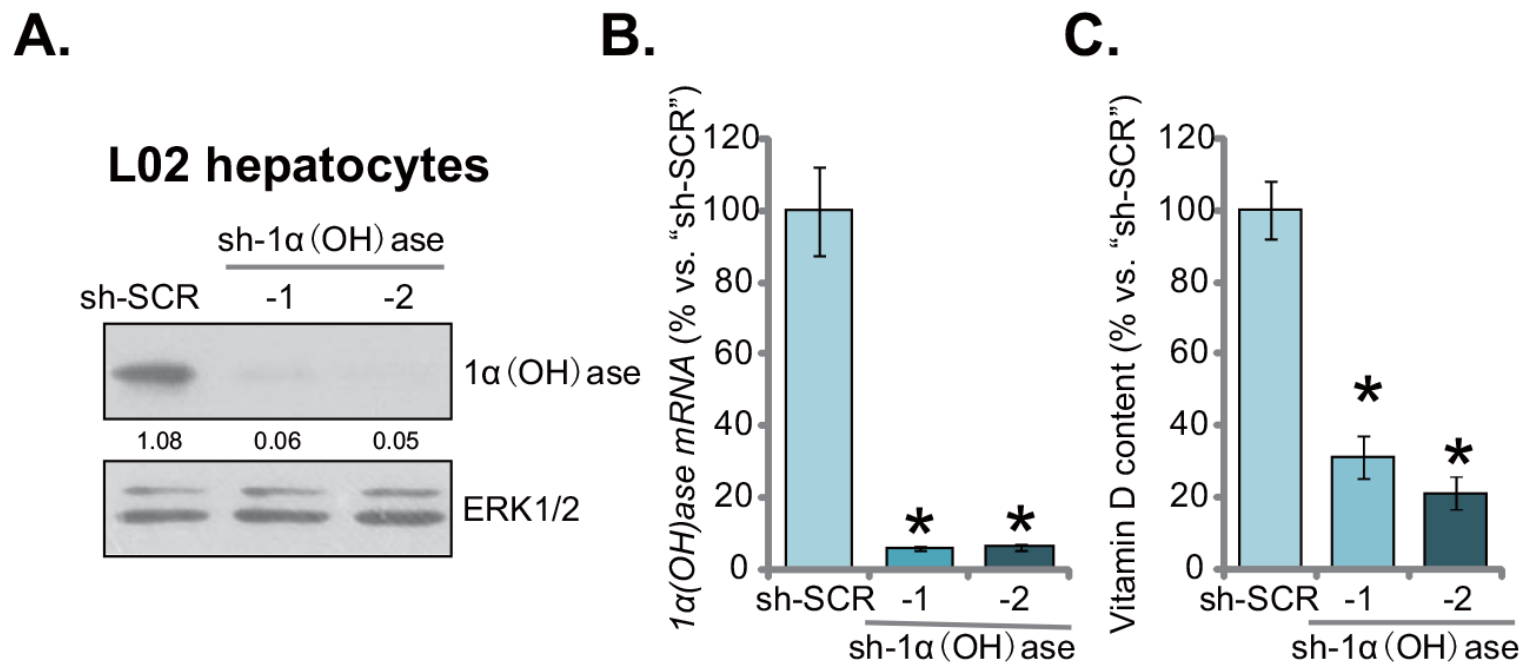

Figure 1: Knockdown of $1 \alpha(\mathrm{OH})$ ase leads to vitamin D3 depletion in L02 hepatocytes. Puromycin-selected stable L02 hepatocytes, expressing shRNA against human $1 \alpha$-Hydroxylase ["sh-1 $\alpha(\mathrm{OH})$ ase-1/-2"] or the scramble control shRNA ("sh-SCR"), were subjected to Western blotting assay (A) and qRT-PCR assay (B) to test $1 \alpha(\mathrm{OH})$ ase expression; Vitamin D3 content in the conditional medium was also analyzed (C). Relative $1 \alpha(\mathrm{OH})$ ase expression (vs. loading control ERK1/2) was quantified (A). Data were expressed as mean $\pm \mathrm{SD}(\mathrm{n}=5) .{ }^{*} p<0.05$ vs. "sh-SCR" cells. Experiments in this and all following figures were repeated three times, and similar results were obtained. 
was also significantly decreased in $1 \alpha(\mathrm{OH})$ ase-silenced L02 hepatocytes (Figure 3A). Consequently, cellular ROS content and subsequent lipid peroxidation intensity were both dramatically increased (Figure 3B and 3C). Thus, $1 \alpha(\mathrm{OH})$ ase knockdown apparently provoked oxidative stress in human L02 hepatocytes (Figure 3B and 3C). Further studies showed that $1 \alpha(\mathrm{OH})$ ase silence in L02 hepatocytes also activated p53-p21 signaling (Figure $3 \mathrm{D})$, which is a key downstream pathway following oxidative stress [20, 21]. Further, level of DNA damage, tested by $\gamma$-H2AX FACS assay, was also increased in L02 hepatocytes expressing $1 \alpha(\mathrm{OH})$ ase shRNAs (Figure 3E).

\section{$\mathrm{N}$-acetylcysteine blocks ROS production, p53-p21 activation and DNA damage in $1 \alpha(\mathrm{OH})$ ase-silenced LO2 hepatocytes}

To study the potential effect of oxidative stress on insulin resistance in $1 \alpha(\mathrm{OH})$ ase-depleted L02 hepatocytes, the well-established anti-oxidant n-acetylcysteine (NAC) $[22,23]$ was applied. Results in Figure 4A confirmed that co-treatment with NAC almost completely blocked oxidative stress in $1 \alpha(\mathrm{OH})$ asesilenced L02 hepatocytes (by "shRNA-1", see Figure 1). ROS level reduced to even lower than control level with NAC co-administration (Figure 4A). Consequently, lipid peroxidation by $1 \alpha(\mathrm{OH})$ ase shRNA was almost completely nullified by NAC (Figure 4B). p53-p21 activation in $1 \alpha(\mathrm{OH})$ ase-silenced cells was also blocked
(Figure 4C). Similarly, $1 \alpha(\mathrm{OH})$ ase silence-induced DNA damage, tested again by the $\gamma-\mathrm{H} 2 \mathrm{AX}$ FACS assay (Figure 4D), was also significantly alleviated with co-treatment of NAC. As expected, NAC cotreatment failed to rescue $1 \alpha(\mathrm{OH})$ ase expression in $\mathrm{L} 02$ hepatocytes (Figure 4C). Together, these results indicate that co-treatment with NAC almost blocked $1 \alpha(\mathrm{OH})$ ase depletion-induced ROS production, p53-p21 activation and DNA damage in L02 hepatocytes.

\section{NAC restores insulin sensitivity in $1 \alpha(\mathrm{OH})$ ase- silenced L02 hepatocytes}

Oxidative stress is proposed as the major cause of insulin resistance [7]. If ROS production is the reason of insulin resistance in $1 \alpha(\mathrm{OH})$ ase-silenced hepatocytes, inhibition of ROS by NAC (see Figure 4) should restore insulin sensitivity. Indeed, as shown in Figure 5A (quantified blot results), insulin-induced downstream signaling activation was recovered with NAC co-treatment in the $1 \alpha(\mathrm{OH})$ ase-silenced cells. In $1 \alpha(\mathrm{OH})$ ase-silenced cells, after co-treatment of NAC, activations of IRS-1, AKT and ERK1/2 by insulin returned to control level ("shSCR") (Figure 5A, quantified blot results). Furthermore, downregulation of GLUT4 by $1 \alpha(\mathrm{OH})$ ase silence was also reversed with NAC co-treatment (Figure 5B). Thus, these results indicate that oxidative stress should be the reason of insulin resistance in $1 \alpha(\mathrm{OH})$ ase-silenced cells, which was reversed with co-treatment of NAC.

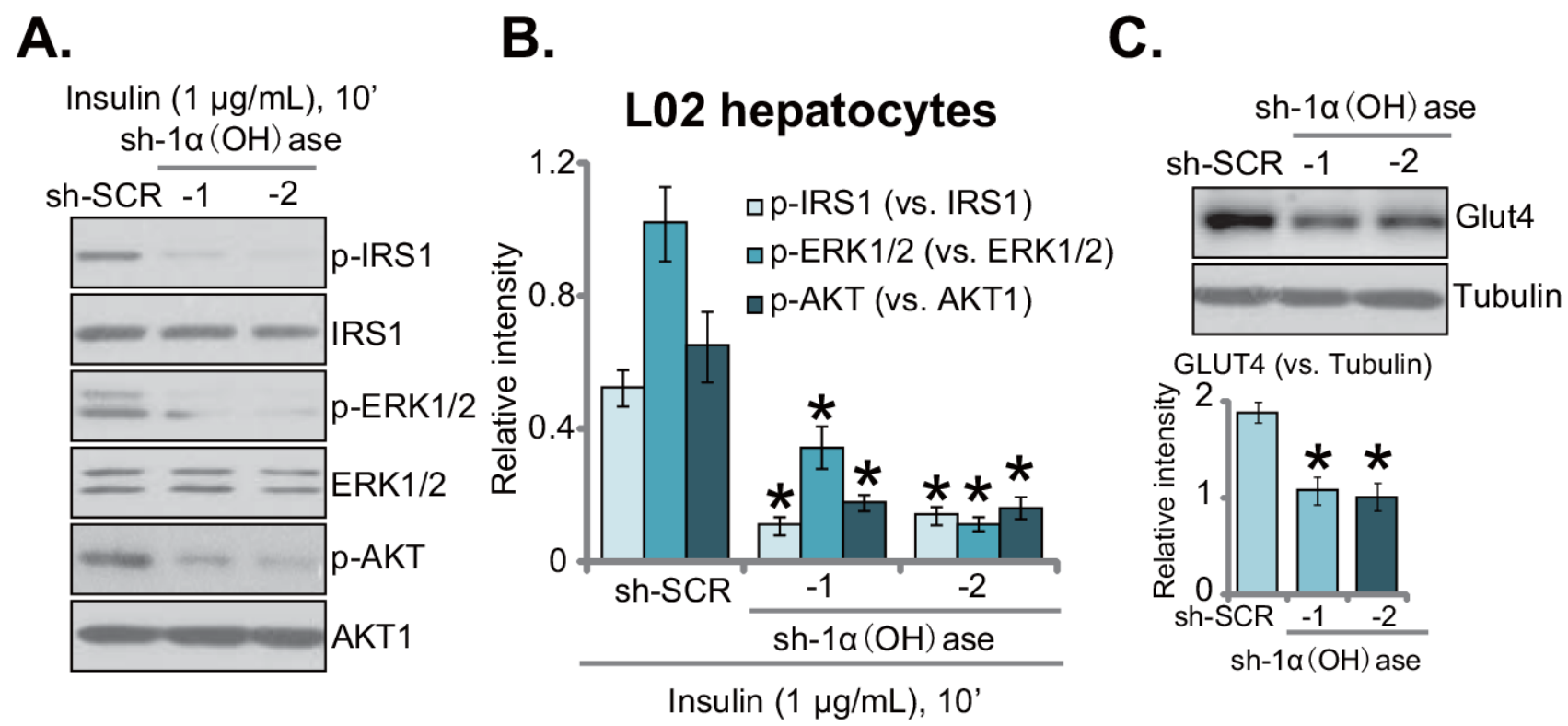

Figure 2: Knockdown of $1 \alpha(\mathrm{OH})$ ase leads to insulin resistance in L02 hepatocytes. Puromycin-selected stable L02 hepatocytes, expressing shRNA against human $1 \alpha$-Hydroxylase ["sh-1 $\alpha(\mathrm{OH})$ ase-1/-2"] or the scramble control shRNA ("sh-SCR"), were treated with insulin $(1 \mu \mathrm{g} / \mathrm{mL}$ ) for $10 \mathrm{~min}$, expressions of listed proteins were tested by Western blotting assay (A); quantified results summarizing three sets of repeated blot data were also shown (B); expressions of GLUT4 and ( $\beta$-) tubulin were also tested, results were also quantified (C). Data were expressed as mean $\pm \mathrm{SD}(\mathrm{n}=3)$. * $p<0.05$ vs. "sh-SCR" cells. 

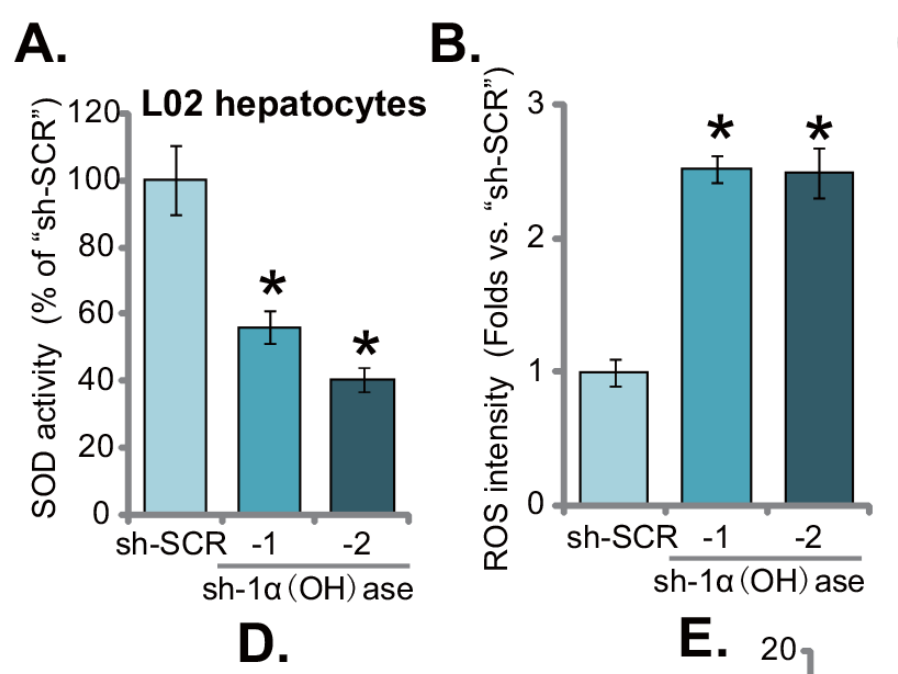

C.
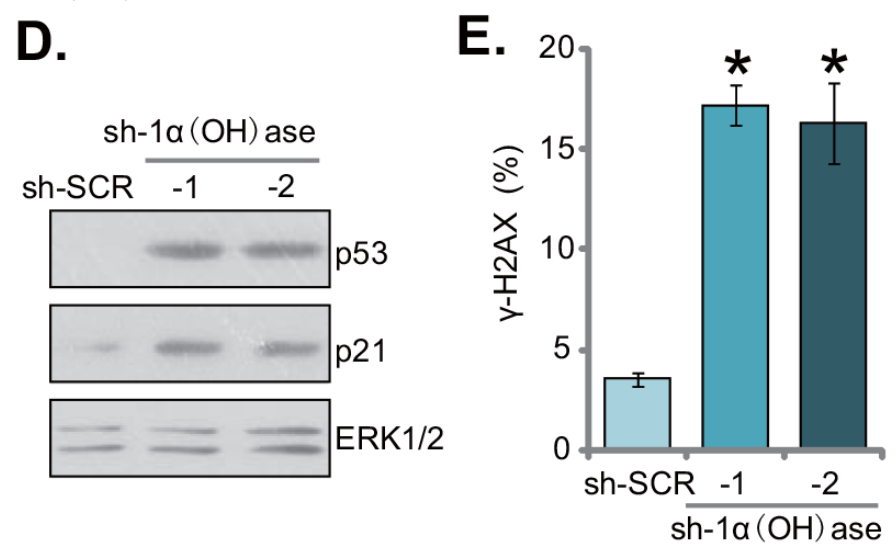

Figure 3: Knockdown of $1 \alpha(\mathrm{OH})$ ase leads to ROS production, p53-p21 activation and DNA damage in L02 hepatocytes. Puromycin-selected stable L02 hepatocytes, expressing shRNA against human $1 \alpha$-Hydroxylase ["sh- $1 \alpha(\mathrm{OH})$ ase-1/-2"] or the scramble control shRNA ("sh-SCR"), were subjected to listed assays to test SOD activity (A), ROS content (DCFH-DA assay) (B), lipid peroxidation level (TBAR assay) (C), p53-p21 signaling (Western blotting assay) (D), and DNA damage ( $\gamma$-H2AX FACS assay) (E). Data were expressed as mean $\pm \mathrm{SD}(\mathrm{n}=5)$. * $p<0.05$ vs. "sh-SCR" cells.

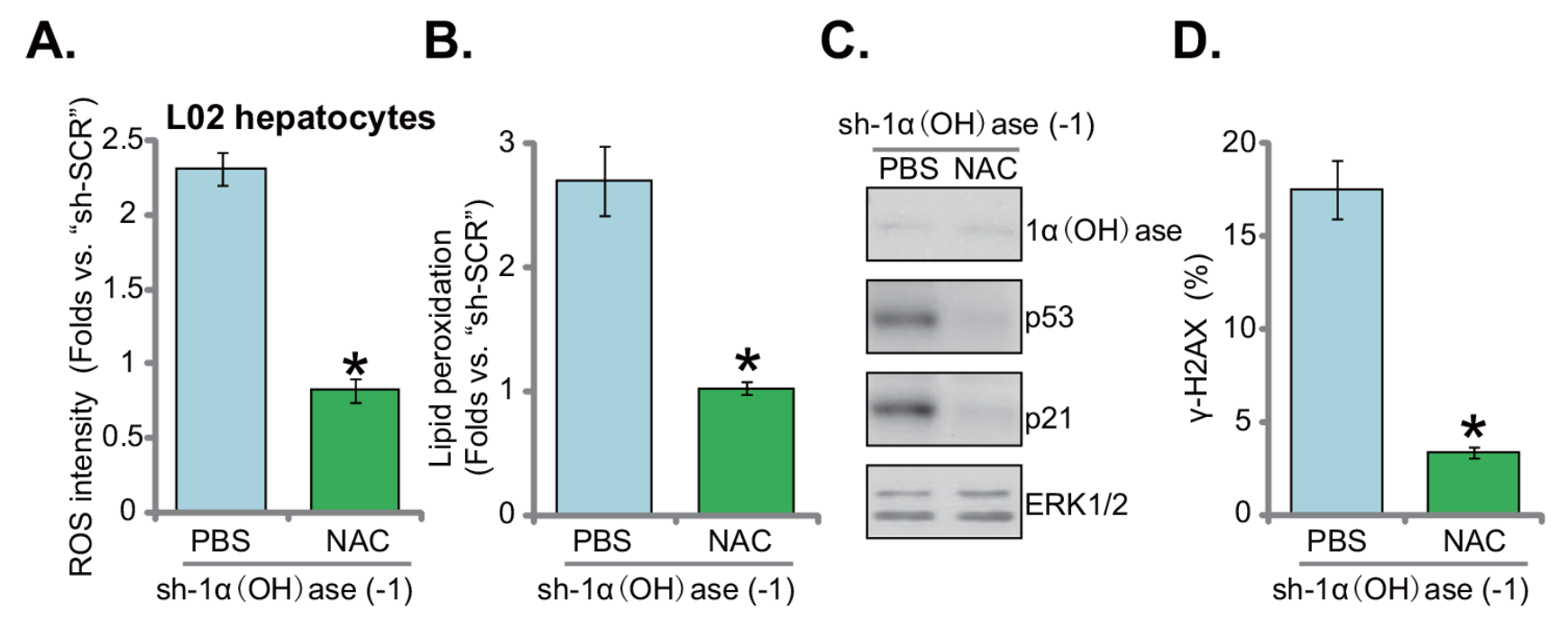

Figure 4: N-acetylcysteine blocks ROS production, p53-p21 activation and DNA damage in 1a(OH)ase-silenced L02 hepatocytes. L02 hepatocytes, infected with shRNA against human $1 \alpha$-Hydroxylase ["sh- $1 \alpha(\mathrm{OH})$ ase-1"], were also exposed to n-acetylcysteine (NAC, $500 \mu \mathrm{M}$, renewed daily) or PBS. After 10 days, relative ROS content (DCFH-DA assay) (A), lipid peroxidation level (TBAR assay) (B) p53-p21 signaling (Western blotting assay) (C), and DNA damage ( $\gamma$-H2AX FACS assay) (D) were tested. Data were expressed as mean $\pm \mathrm{SD}(\mathrm{n}=5) . * p<0.05$ vs. "PBS" cells. 


\section{DISCUSSION}

Vitamin D is a key hormone that is vital in the regulation of mineral homeostasis. It is mainly involved in bone and calcium/phosphorus balance. Recent studies have implied its function in the pathogenesis of insulin resistance and type II diabetes [6, 24-27]. It has been implied that vitamin D level is negatively associated with insulin resistance, glucose intolerance and obesity [6, 24, 26]. Meanwhile, clinical trials have also suggested an inverse link between vitamin D concentration and type II diabetes $[6,25]$. In the experimental mice with $1 \alpha(\mathrm{OH})$ ase deficiency, insulin resistance and hyperglycemia were also developed [28, 29]. More importantly, exogenous supplementation of active vitamin D3 could decrease the incidence of insulin resistance [6, 24-27]. Thus, vitamin D deficiency could be associated with insulin resistance and type II diabetes, yet the underlying mechanisms are largely unknown [6, 24-27]. In the current study, we showed that vitamin D deficiency via stably silencing $1 \alpha(\mathrm{OH})$ ase also caused insulin resistance in L02 hepatocytes, showing impaired insulin signaling and downregulation of GLUT4.

It has been proposed that vitamin D could increase the release of some anti-inflammatory cytokines, whiling decreasing the production of some pro-inflammatory cytokines [25, 30, 31]. Other studies, however, showed that vitamin D supplementation in humans showed no beneficial effect on inflammation [6]. Existing studies have also proposed vitamin $\mathrm{D}$, especially its active D3 form, as an effective antioxidant [17, 18, 32, 33]. Systemic administration of vitamin D3 attenuated ironinduced oxidative damage in brains [17, 18, 32, 33]. Vitamin D3 could promote expression of several antioxidative genes, including $\gamma$-glutamyl transpeptidase (GGT), glutathione, glutathione peroxidase (GPx), and SOD, among others $[17,18,32,33]$. On the other hand, vitamin D-deficiency would lead to oxidative stresses [17, $18,32,33]$.

In the current study, we proposed that oxidative stress could be the main reason of insulin resistance in vitamin D-deficient cells. Vitamin D depletion via stably silencing $1 \alpha(\mathrm{OH})$ ase in L02 hepatocytes led to significant ROS production, as well as subsequent p53-p21 activation and DNA damage. Such effects were almost completely nullified with co-treatment of NAC, the known antioxidant. Remarkably, insulin resistance was also abolished with co-treatment of NAC in $1 \alpha(\mathrm{OH})$ ase-depleted L02 hepatocytes. Together, our results suggest that vitamin D deficiency-induced insulin resistance is possibly caused by oxidative stress in L02 hepatocytes.

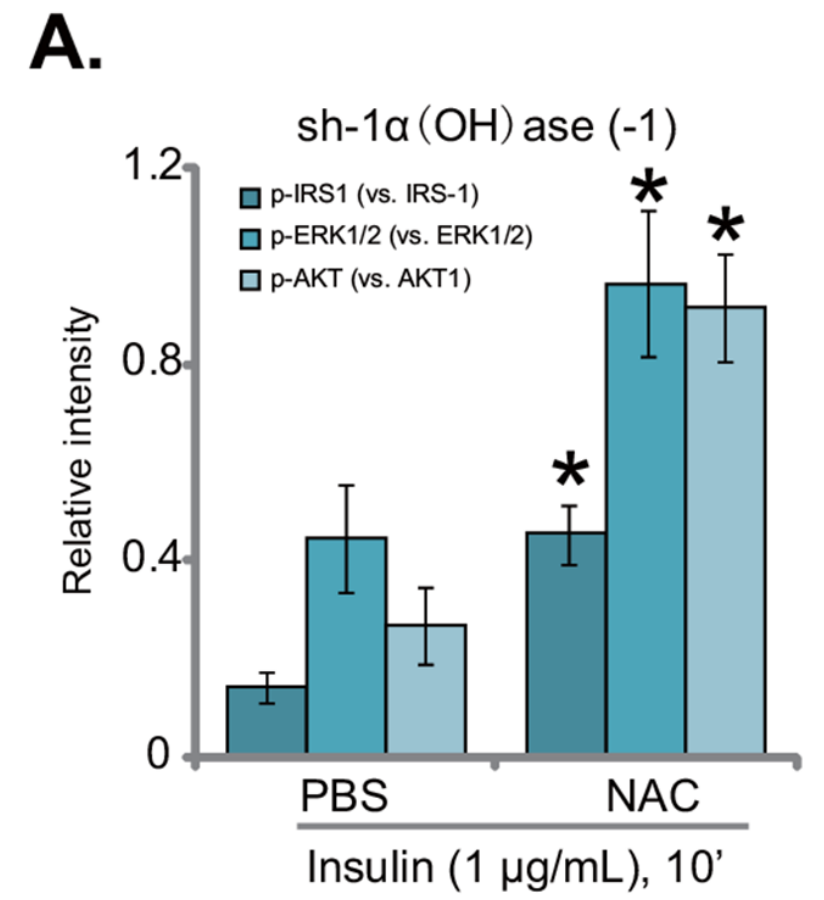

B.

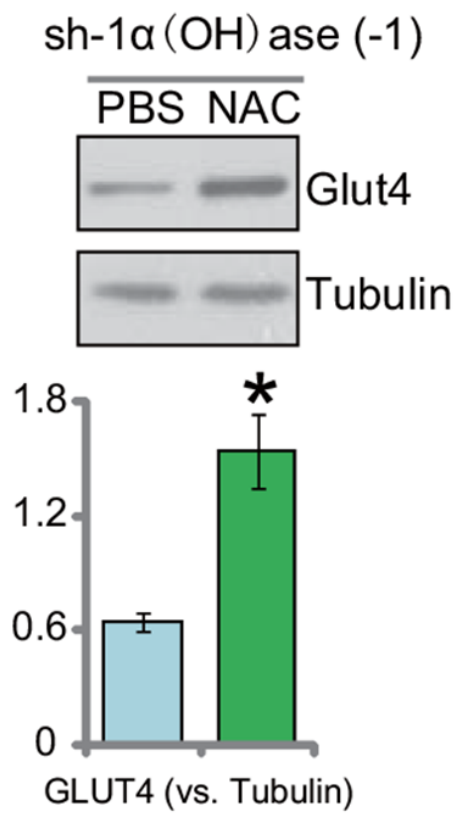

Figure 5: NAC restores insulin sensitivity in $1 \alpha(\mathrm{OH})$ ase-silenced L02 hepatocytes. L02 hepatocytes, infected with shRNA against human $1 \alpha$-Hydroxylase ["sh-1 $\alpha(\mathrm{OH})$ ase-1"], were also exposed to n-acetylcysteine (NAC, $500 \mu \mathrm{M}$, renewed daily) or PBS; After 10 days, cells were treated with insulin $(1 \mu \mathrm{g} / \mathrm{mL})$ for $10 \mathrm{~min}$, expressions of listed proteins were tested by Western blotting assay, and results of three sets of repeats were quantified (A); expressions of GLUT4 and tubulin were also tested. (B) Quantified results summarizing three sets of repeated blot data were also shown). Data were expressed as mean $\pm \mathrm{SD}(\mathrm{n}=3)$. * $p<0.05$ vs. "PBS" cells. 


\section{MATERIALS AND METHODS}

\section{Chemicals and reagents}

Insulin, n-acetylcysteine (NAC) and puromycin were provided by Sigma Aldrich Chemicals (Nanjing, China). The antibodies of this study were provided by Cell Signaling Technology (Danvers, MA) and Abcam (Shanghai, China). The reagents for cell culture were obtained from Gibco Co. (Nantong, China).

\section{Cell culture}

Human L02 hepatocytes were provided by the Cell Bank of Shanghai Biological Institute (Shanghai, China). L02 cells were cultured in RPMI 1640 with $10 \%$ FBS and antibiotics, in a humidified atmosphere at $37^{\circ} \mathrm{C}$ with $5 \%$ $\mathrm{CO}_{2}$. Cells were subjected to mycoplasma and microbial contamination examination every 2-3 months. Population doubling time, colony forming efficiency, and morphology were routinely checked to confirm the genotype.

\section{$1 \alpha(\mathrm{OH})$ ase shRNA}

The two lentiviral $1 \alpha(\mathrm{OH})$ ase shRNAs with nonoverlapping sequences were designed and verified by Genepharm (Shanghai, China). The shRNA $(10 \mu \mathrm{L} / \mathrm{mL}$ medium, per well) was added to L02 hepatocytes for 24 hours. Stable cells were selected by puromycin $(0.5 \mu \mathrm{g} /$ $\mathrm{mL}$, Sigma) for a total of 10 days. Puromycin-containing medium was renewed every two days. Silence of $1 \alpha(\mathrm{OH})$ ase in the stable L02 hepatocytes was confirmed by both qRT-PCR assay and Western blotting assay. Control cells were infected with lentiviral scramble control shRNA (Santa Cruz Biotech).

\section{Vitamin D3 assay}

The level of vitamin D3 in the conditional medium of L02 hepatocytes were tested via a commercial available enzyme linked fluorescent assay (ELFA) kit from Roche (Shanghai, China), according to the manufacturer's guidelines.

\section{RNA isolation and qRT-PCR}

As described in our previous studies [34, 35], Trizol reagents (Invitrogen) was applied to extract the total RNA of L02 hepatocytes. RNA was then reversetranscribed (RT) with RT-PCR kit (Toyobo, Osaka, Japan). Quantitative Real-time PCR (“qRT-PCR") assay using the SYBR green kit was performed using the ABI-7600 PCR system (Applied Biosystems, Shanghai, China). mRNA primers of $1 \alpha(\mathrm{OH})$ ase and $G A P D H$ were described previously $[36,37]$. We utilized the $2^{\Delta \Delta \mathrm{Ct}}$ method to calculate relative $1 \alpha(\mathrm{OH})$ ase mRNA expression (vs. $G A P D H)$. All the primers were synthesized by Genepharm (Shanghai, China).

\section{Western blotting assay}

First, the lysis buffer (Biyuntian, Wuxi, China) was applied to achieve protein lysates from L02 hepatocytes. For each condition, $30 \mu \mathrm{g}$ total lysate proteins per lane were separated by the SDS-PAGE gels (10-12\%) [16, 38], which were then transferred to the polyvinylidene difluoride (PVDF, Millipore, Suzhou, China) membranes. Afterwards, the blots were blocked (in 10\% of milk), and were incubated with designated primary and corresponding secondary antibodies. Enhanced chemiluminescence (ECL) reagents (Pierce, Nantong, China) were utilized to visual the interested bands [39-41]. Total gray of each band was quantified via the ImageJ software, and the value was normalized to that of loading control (ERK1/2 or $\beta$-Tubulin).

\section{SOD activity assay}

The superoxide dismutase (SOD) activity in L02 hepatocytes was assayed by the NWLSS kit, which is an extremely sensitive SOD kit, using WST-1 to generate a water-soluble formazan dye upon reduction with superoxide anion. The detailed procedure was described previously [42]. The final mixture was subjected to spectrophotometer detection at the absorbance at $560 \mathrm{~nm}$.

\section{Reactive oxygen species (ROS) assay}

ROS content was tested by the DCFH-DA fluorescent dye assay (Invitrogen). The detailed protocol was described in our previous studies [34, 35, 41]. Briefly, after applied treatment, L02 hepatocytes were incubated with $10 \mu \mathrm{M}$ of DCFH-DA for 30 min under the dark, which were thereafter tested for fluorescence under a Fluorescence Microplate Reader (Synergy 2, BioTek, Winooski, VT).

\section{Lipid peroxidation assay}

As described previously [43], cellular lipid peroxidation was evaluated by the thiobarbituric acid reactive substances (TBAR) assay [44]. Briefly, after the indicated treatment, L02 hepatocytes protein lysates (20 $\mu \mathrm{g}$ per condition) were mixed with $20 \%$ of acetic acid and thiobarbituric acid solution. After heating, the mixtures were centrifuged, and then in the supernatant the red pigment dye was tested via a microplate reader. TBAR activity was expressed as $\mathrm{nM}$ of malondialdehyde per $\mathrm{mg}$ protein. The values of treatment group were always normalized to control. 


\section{$\gamma$-H2AX FACS assay}

$\gamma$-H2AX assay was performed to test DNA damage. Briefly, L02 hepatocytes were first trypsinized and fixed in ice-cold ethanol, which were then exposed to the anti$\gamma$-H2AX antibody (Cellular Signaling Tech) for 6 hours. Cells were then incubated with the FITC-conjugated secondary antibody. FACS assay was performed to determine $\gamma-\mathrm{H} 2 \mathrm{AX}$ percentage, as the quantitative measurement of DNA damage [45].

\section{Statistical analysis}

The results were expressed as mean \pm standard deviation (SD). The statistical analysis among different groups was done using one-way ANOVA with Scheffe's test $[46,47]$.

\section{Author contributions}

All authors carried out the experiments, participated in the design of the study and performed the statistical analysis, participated in its design and coordination and helped to draft the manuscript.

\section{ACKNOWLEDGMENTS}

This work is supported by the National Natural Science Foundation (81400789), and by the Natural Science Foundation of Jiangsu Province (BK20140459).

\section{CONFLICTS OF INTEREST}

The listed authors have no conflicts of interest.

\section{REFERENCES}

1. Zhao X, Liu X, Wang G, Wen X, Zhang X, Hoffman AR, Li W, Hu JF, Cui J. Loss of insulin-like growth factor II imprinting is a hallmark associated with enhanced chemo/ radiotherapy resistance in cancer stem cells. Oncotarget. 2016; 7:51349-51364. doi: 10.18632/oncotarget.9784.

2. Kang YH, Cho MH, Kim JY, Kwon MS, Peak JJ, Kang SW, Yoon SY, Song Y. Impaired macrophage autophagy induces systemic insulin resistance in obesity. Oncotarget. 2016; 7:35577-35591. doi: 10.18632/oncotarget.9590.

3. Greenhill C. Metabolism: contribution of B cells to obesity and insulin resistance. Nat Rev Endocrinol. 2013; 9:315.

4. Guilherme A, Virbasius JV, Puri V, Czech MP. Adipocyte dysfunctions linking obesity to insulin resistance and type 2 diabetes. Nat Rev Mol Cell Biol. 2008; 9:367-377.

5. Muoio DM, Newgard CB. Mechanisms of disease: molecular and metabolic mechanisms of insulin resistance and beta-cell failure in type 2 diabetes. Nat Rev Mol Cell Biol. 2008; 9:193-205.
6. Berridge MJ. Vitamin D deficiency and diabetes. Biochem J. 2017; 474:1321-1332.

7. Houstis N, Rosen ED, Lander ES. Reactive oxygen species have a causal role in multiple forms of insulin resistance. Nature. 2006; 440:944-948.

8. Evans JL, Goldfine ID, Maddux BA, Grodsky GM. Are oxidative stress-activated signaling pathways mediators of insulin resistance and beta-cell dysfunction? Diabetes. $2003 ; 52: 1-8$.

9. Bloch-Damti A, Bashan N. Proposed mechanisms for the induction of insulin resistance by oxidative stress. Antioxid Redox Signal. 2005; 7:1553-1567.

10. Panigrahy SK, Bhatt R, Kumar A. Reactive oxygen species: sources, consequences and targeted therapy in type 2 diabetes. J Drug Target. 2017; 25:93-101.

11. Tiganis T. Reactive oxygen species and insulin resistance: the good, the bad and the ugly. Trends Pharmacol Sci. 2011; 32:82-89.

12. Busija DW, Miller AW, Katakam P, Erdos B. Adverse effects of reactive oxygen species on vascular reactivity in insulin resistance. Antioxid Redox Signal. 2006; 8:1131-1140.

13. Takeyama K, Kitanaka S, Sato T, Kobori M, Yanagisawa J, Kato S. 25-Hydroxyvitamin D3 1alpha-hydroxylase and vitamin D synthesis. Science. 1997; 277:1827-1830.

14. Grant WB. 25-hydroxyvitamin D and breast cancer, colorectal cancer, and colorectal adenomas: case-control versus nested case-control studies. Anticancer Res. 2015; 35:1153-1160.

15. Zhou J, Wang J, Zeng Y, Zhang X, Hu Q, Zheng J, Chen B, Xie B, Zhang WM. Implication of epithelial-mesenchymal transition in IGF1R-induced resistance to EGFR-TKIs in advanced non-small cell lung cancer. Oncotarget. 2015; 6:44332-44345. doi: 10.18632/oncotarget.6293.

16. Leyh B, Dittmer A, Lange T, Martens JW, Dittmer J. Stromal cells promote anti-estrogen resistance of breast cancer cells through an insulin-like growth factor binding protein 5 (IGFBP5)/B-cell leukemia/lymphoma 3 (Bcl-3) axis. Oncotarget. 2015; 6:39307-39328. doi: 10.18632/ oncotarget.5624.

17. Ravid A, Koren R. The role of reactive oxygen species in the anticancer activity of vitamin D. Recent Results Cancer Res. 2003; 164:357-367.

18. Nikooyeh B, Neyestani TR. Oxidative stress, type 2 diabetes and vitamin D: past, present and future. Diabetes Metab Res Rev. 2016; 32:260-267.

19. Hamden K, Carreau S, Jamoussi K, Miladi S, Lajmi S, Aloulou D, Ayadi F, Elfeki A. 1Alpha,25 dihydroxyvitamin D3: therapeutic and preventive effects against oxidative stress, hepatic, pancreatic and renal injury in alloxaninduced diabetes in rats. J Nutr Sci Vitaminol (Tokyo). 2009; 55:215-222.

20. Vurusaner B, Poli G, Basaga H. Tumor suppressor genes and ROS: complex networks of interactions. Free Radic Biol Med. 2012; 52:7-18. 
21. Esposito F, Russo L, Chirico G, Ammendola R, Russo T, Cimino F. Regulation of p21waf1/cip1 expression by intracellular redox conditions. IUBMB Life. 2001; 52:67-70.

22. Zhang X, Wang YN, Zhu JJ, Liu XX, You H, Gong MY, Zou M, Cheng WH, Zhu JH. N-acetylcysteine negatively regulates Notch3 and its malignant signaling. Oncotarget. 2016; 7:30855-30866. doi: 10.18632/oncotarget.8806.

23. Amini A, Masoumi-Moghaddam S, Ehteda A, Liauw W, Morris DL. Depletion of mucin in mucin-producing human gastrointestinal carcinoma: results from in vitro and in vivo studies with bromelain and $\mathrm{N}$-acetylcysteine. Oncotarget. 2015; 6:33329-33344. doi: 10.18632/oncotarget.5259.

24. Fondjo LA, Owiredu W, Sakyi SA, Laing EF, AdoteyKwofie MA, Antoh EO, Detoh E. Vitamin D status and its association with insulin resistance among type 2 diabetics: a case -control study in Ghana. PLoS One. 2017; 12:e0175388.

25. Garbossa SG, Folli F. Vitamin D, sub-inflammation and insulin resistance. A window on a potential role for the interaction between bone and glucose metabolism. Rev Endocr Metab Disord. 2017; 18:243-258.

26. Karamali M, Ashrafi M, Razavi M, Jamilian M, Kashanian M, Akbari M, Asemi Z. The effects of calcium, vitamins $\mathrm{D}$ and $\mathrm{K}$ co-supplementation on markers of insulin metabolism and lipid profiles in vitamin D-deficient women with polycystic ovary syndrome. Exp Clin Endocrinol Diabetes. 2017; 125:316-321.

27. Verrusio W, Andreozzi P, Renzi A, Musumeci M, Gueli N, Cacciafesta M. Association between serum vitamin D and metabolic syndrome in middle-aged and older adults and role of supplementation therapy with vitamin D. Ann Ist Super Sanita. 2017; 53:54-59.

28. Park S, Kim DS, Kang S. Vitamin D deficiency impairs glucose-stimulated insulin secretion and increases insulin resistance by reducing PPAR-gamma expression in nonobese Type 2 diabetic rats. J Nutr Biochem. 2016; 27:257-265.

29. Takiishi T, Van Belle T, Gysemans C, Mathieu C. Effects of vitamin $\mathrm{D}$ on antigen-specific and non-antigen-specific immune modulation: relevance for type 1 diabetes. Pediatr Diabetes. 2013; 14:81-89.

30. Dimitrov V, White JH. Vitamin D signaling in intestinal innate immunity and homeostasis. Mol Cell Endocrinol. 2017 Apr 12. doi: 10.1016/j.mce.2017.04.010. [Epub ahead of print]

31. Clark A, Mach N. Role of vitamin D in the hygiene hypothesis: the interplay between vitamin D, vitamin D receptors, gut microbiota, and immune response. Front Immunol. 2016; 7:627.

32. Wrzosek M, Lukaszkiewicz J, Jakubczyk A, Matsumoto H, Piatkiewicz P, Radziwon-Zaleska M, Wojnar M, Nowicka
G. Vitamin D and the central nervous system. Pharmacol Rep. 2013; 65:271-278.

33. Nair-Shalliker V, Armstrong BK, Fenech M. Does vitamin D protect against DNA damage? Mutat Res. 2012; 733:50-57.

34. Liu W, Mao L, Ji F, Chen F, Wang S, Xie Y. Icariside II activates EGFR-Akt-Nrf2 signaling and protects osteoblasts from dexamethasone. Oncotarget. 2017; 8:2594-2603. doi: 10.18632/oncotarget.13732.

35. Liu W, Mao L, Ji F, Chen F, Hao Y, Liu G. Targeted activation of AMPK by GSK621 ameliorates H2O2-induced damages in osteoblasts. Oncotarget. 2017; 8:10543-10552. doi: 10.18632/oncotarget.14454.

36. Panda DK, Miao D, Bolivar I, Li J, Huo R, Hendy GN, Goltzman D. Inactivation of the 25-hydroxyvitamin D 1alpha-hydroxylase and vitamin D receptor demonstrates independent and interdependent effects of calcium and vitamin D on skeletal and mineral homeostasis. J Biol Chem. 2004; 279:16754-16766.

37. Schwartz GG, Eads D, Rao A, Cramer SD, Willingham MC, Chen TC, Jamieson DP, Wang L, Burnstein KL, Holick MF, Koumenis C. Pancreatic cancer cells express 25-hydroxyvitamin D-1 alpha-hydroxylase and their proliferation is inhibited by the prohormone 25-hydroxyvitamin D3. Carcinogenesis. 2004; 25:1015-1026.

38. Canella A, Cordero Nieves H, Sborov DW, Cascione L, Radomska HS, Smith E, Stiff A, Consiglio J, Caserta E, Rizzotto L, Zanesi N, Stefano V, Kaur B, et al. HDAC inhibitor AR-42 decreases CD44 expression and sensitizes myeloma cells to lenalidomide. Oncotarget. 2015; 6:3113431150. doi: 10.18632/oncotarget.5290.

39. Guo S, Xie Y, Fan JB, Ji F, Wang S, Fei H. $\alpha$-Melanocyte stimulating hormone attenuates dexamethasone-induced osteoblast damages through activating melanocortin receptor 4-SphK1 signaling. Biochem Biophys Res Commun. 2016; 469:281-287.

40. Ji F, Mao L, Liu Y, Cao X, Xie Y, Wang S, Fei H. K6PC-5, a novel sphingosine kinase 1 (SphK1) activator, alleviates dexamethasone-induced damages to osteoblasts through activating SphK1-Akt signaling. Biochem Biophys Res Commun. 2015; 458:568-575.

41. Guo S, Mao L, Ji F, Wang S, Xie Y, Fei H, Wang XD. Activating AMP-activated protein kinase by an alpha1 selective activator compound 13 attenuates dexamethasoneinduced osteoblast cell death. Biochem Biophys Res Commun. 2016; 471:545-552.

42. In S, Hong CW, Choi B, Jang BG, Kim MJ. Inhibition of mitochondrial clearance and $\mathrm{Cu} / \mathrm{Zn}-\mathrm{SOD}$ activity enhance 6-hydroxydopamine-induced neuronal apoptosis. Mol Neurobiol. 2016; 53:777-791.

43. Kwon MY, Park E, Lee SJ, Chung SW. Heme oxygenase-1 accelerates erastin-induced ferroptotic cell death. 
Oncotarget. 2015; 6:24393-24403. doi: 10.18632/ oncotarget.5162.

44. Cortizo AM, Bruzzone L, Molinuevo S, Etcheverry SB. A possible role of oxidative stress in the vanadium-induced cytotoxicity in the MC3T3E1 osteoblast and UMR106 osteosarcoma cell lines. Toxicology. 2000; 147:89-99.

45. Ewald B, Sampath D, Plunkett W. H2AX phosphorylation marks gemcitabine-induced stalled replication forks and their collapse upon S-phase checkpoint abrogation. Mol Cancer Ther. 2007; 6:1239-1248.
46. Zhu YR, Zhou XZ, Zhu LQ, Yao C, Fang JF, Zhou F, Deng $\mathrm{XW}$, Zhang YQ. The anti-cancer activity of the mTORC1/2 dual inhibitor XL388 in preclinical osteosarcoma models. Oncotarget. 2016; 7:49527-49538. doi: 10.18632/ oncotarget.10389.

47. Law BY, Mok SW, Chan WK, Xu SW, Wu AG, Yao XJ, Wang JR, Liu L, Wong VK. Hernandezine, a novel AMPK activator induces autophagic cell death in drug-resistant cancers. Oncotarget. 2016; 7:8090-8104. doi: 10.18632/ oncotarget. 6980 . 